\title{
Les propriétés biotiques et abiotiques des gîtes larvaires d'Aedes aegypti et leur influence sur les traits de vie des adultes (synthèse bibliographique)
}

\author{
Lyza Hery, Antoine Boullis, Anubis Vega-Rúa
}

Institut Pasteur de la Guadeloupe. Laboratoire d'études sur le contrôle des vecteurs. Unité transmission, réservoir et diversité des pathogènes. Morne Jolivière. F-97139 Les Abymes. Guadeloupe (France). E-mail : lhery@pasteur-guadeloupe.fr

Reçu le 20 mars 2020, accepté le 3 mars 2021, mis en ligne le 25 mars 2021.

Cet article est distribué suivant les termes et les conditions de la licence CC-BY (http://creativecommons.org/licenses/by/4.0/ deed.fr)

Introduction. Le moustique Aedes aegypti, vecteur majeur d'arbovirus, se développe dans un large panel de réservoirs artificiels en zone urbaine. Ces gîtes larvaires sont exposés à des conditions biotiques et abiotiques variables pouvant influencer la capacité vectorielle du moustique adulte et, par conséquent, le risque de transmission de pathogènes. Ici, nous recensons l'état des connaissances sur les propriétés physico-chimiques et microbiologiques des habitats aquatiques d'Ae.aegypti qui affectent le comportement de pré-oviposition, le développement et la capacité à transmettre les virus de ce Culicidae.

Littérature. La grande variabilité spatio-temporelle des propriétés abiotiques et biotiques des gîtes d'Ae.aegypti rend complexe leur caractérisation. Certains facteurs biotiques (matière organique, larves congénères, microbiote) et abiotiques (salinité, température, $\mathrm{pH}$ ) des gîtes ont des effets forts et directs sur le développement des larves et se répercutent sur les caractéristiques physiologiques et morphologiques du moustique adulte telles que la taille, la fécondité, la longévité et sa capacité vectorielle.

Conclusions. Au vu de l'influence du gîte larvaire, et notamment de son microbiote, sur des nombreux traits phénotypiques chez Ae. aegypti, des efforts sont encore requis pour mieux comprendre comment la variabilité naturelle des gîtes façonne la capacité vectorielle des populations de cette espèce invasive à travers le globe.

Mots-clés. Aedes aegypti, réservoirs d'eau, facteurs abiotiques, microbiote, oviposition, transmission des maladies.

Biotic and abiotic properties of Aedes aegypti breeding sites and their influence on adult phenotypic traits. A review Introduction. The Aedes aegypti mosquito, a major vector of arbovirus, develops in a wide range of artificial reservoirs in urban areas. These breeding sites are exposed to variable biotic and abiotic conditions that can influence the vectorial capacity of the adult mosquito and consequently the risk of pathogen transmission. Here, we review the state of knowledge on the physicochemical and microbiological properties of Ae. aegypti breeding sites that affect the pre-oviposition behavior, development and virus transmission capacity of this Culicidae.

Literature. The high spatial and temporal variability of the abiotic and biotic properties of Ae. aegypti breeding sites makes their characterization complex. Some biotic (organic matter, congeneric larvae, microbiota) and abiotic (salinity, temperature, $\mathrm{pH}$ ) factors of the breeding sites have strong and direct effects on larvae development and have repercussions on the physiological and morphological characteristics of the adult mosquito, such as size, fecundity and vectorial capacity.

Conclusions. In view of the influence of the larval aquatic habitat, and in particular its microbiota, on many phenotypic traits in Ae.aegypti, efforts are still required to better understand how the natural variability of breeding sites shapes the vectorial capacity of populations of this invasive species worldwide.

Keywords. Aedes aegypti, water reservoirs, abiotic factors, microbiome, oviposition, disease transmission.

\section{INTRODUCTION}

Le moustique Aedes (Stegomyia) aegypti (Diptère: Culicidae) est connu pour être le principal vecteur de nombreuses arboviroses d'intérêt majeur en santé humaine. C'est notamment le cas pour les virus de la fièvre jaune, de la dengue (VDEN), du chikungunya (VCHIK) et du Zika (VZIK) qui peuvent provoquer 
chez l'homme des symptômes bénins (i.e. forte fièvre, douleurs articulaires), mais aussi des hémorragies mortelles(VDEN)et/oudescomplications neurologiques (VZIK) (Souza-Neto et al., 2019). À l'heure actuelle, le contrôle des populations de moustiques vecteurs est la seule stratégie disponible pour prévenir ces maladies, car il n'existe pas de traitement thérapeutique ou de méthodes prophylactiques efficaces contre ces arbovirus (Silva et al., 2018). Les moustiques sont des organismes holométaboles dont le cycle de vie comporte deux phases :

- la phase immature aquatique qui commence à partir des œufs, d'où éclosent les larves qui se développent en nymphes dans des habitats appelés «gîtes larvaires » ou « sites de ponte »;

- la phase adulte aérienne qui débute avec l'émergence de l'imago (Clements, 2000).

L'abondance et la distribution des moustiques sont étroitement liées aux gîtes larvaires qui sont favorables à leur reproduction. Le choix du gîte par la femelle est influencé par de nombreux facteurs tels que les types de récipients (i.e. dimensions, couleurs, nature) ou la qualité de l'eau, et peut avoir des conséquences importantes pour l'épidémiologie des arboviroses. En effet, la présence en zone urbaine de gîtes propices à la croissance des espèces culicidiennes anthropophiles et vectrices d'arbovirus augmente considérablement les probabilités de contact moustique-homme et, par conséquent, le risque de transmission de ces arbovirus. De plus, certaines études soulignent l'influence de l'environnement larvaire, et notamment du microbiote aquatique, sur la biologie du moustique et, en particulier, son aptitude à transmettre les virus (Dickson et al., 2017 ; Moltini-Conclois et al., 2018).

Les premières connaissances sur les gîtes larvaires d'Ae.aegypti ont permis de développer des méthodes de lutte antivectorielle qui visent à rendre l'environnement impropre à leur développement (i.e. application du Bacillus thuringiensis var israelensis) (OMS, 2009). Cependant, les efforts de lutte actuels ne suffisent pas à prévenir les épidémies d'arbovirus. Une compréhension détaillée des facteurs écologiques pouvant favoriser l'établissement, la prolifération de l'espèce Ae.aegypti et la transmission des pathogènes est alors essentielle pour réduire les abondances de l'espèce et le risque de transmission de pathogènes aux populations humaines.

Malheureusement, les connaissances relatives aux paramètres abiotiques et biotiques des gîtes restent parcellaires et leur influence sur les traits phénotypiques des moustiques adultes est toujours insuffisamment étudiée. Cette synthèse bibliographique recense alors l'état actuel des connaissances sur la typologie, les caractéristiques physicochimiques, la composition microbienne des gîtes larvaires d'Ae.aegypti et l'influence de ces facteurs de l'environnement larvaire sur le phénotype du moustique adulte.

\section{LE CHOIX DU GÎTE LARVAIRE PAR LA FEMELLE AE. AEGYPTI}

Après la phase d'accouplement et la prise d'un repas sanguin, les femelles gravides passent par une période de recherche de site de ponte (comportement de pré-oviposition) (Day, 2016). Les femelles peuvent distinguer les sites bénéfiques pour le développement et la survie de leur progéniture plutôt que de les coloniser aléatoirement (Ponnusamy et al., 2008 ; Day, 2016). Ce choix du gîte semble dépendre de repères visuels, olfactifs et tactiles (Day, 2016; Matthews et al., 2019). Les repères visuels permettraient aux femelles d'identifier les habitats aquatiques disponibles et leurs caractéristiques (i.e. couleur, taille, ensoleillement) à l'échelle du paysage, tandis que les repères olfactifs et tactiles deviendraient plus importants à mesure que les moustiques approchent du gîte afin d'évaluer la qualité de l'eau (Day, 2016). La perturbation de ce processus de sélection du gîte peut être bénéfique pour élaborer des méthodes de contrôle des larves, en attirant les femelles vers un site moins favorable (i.e. traité avec un larvicide).

Les femelles Ae.aegypti colonisent préférentiellement les réservoirs "artificiels » d'origine anthropique contenant de l'eau stagnante, le plus souvent autour des maisons (OMS, 2011). Les gîtes particulièrement abondants et/ou qui produisent un plus grand nombre de larves sont qualifiés de « gîtes productifs »(OMS, 2011). Bien que la productivité d'Ae.aegypti augmente positivement avec la taille du conteneur et le volume d'eau (Barrera et al., 2006 ; Islam et al., 2019), la grande majorité des gîtes observés sur le terrain sont de petits récipients (Dom et al., 2013 ; Saleh et al., 2018). Les gîtes productifs d'Ae.aegypti sont très variés d'une région à l'autre : les pneus usés sont souvent cités comme des gîtes productifs sur le continent africain (Philbert \& Ijumba, 2013 ; Abílio et al., 2018), les sceaux et petits récipients en plastique sont les gîtes prédominants en Asie du Sud-Est (Ferdousi et al., 2015 ; Dom et al., 2016), tandis que les barils et les pots de fleurs sont plus productifs dans les îles des Caraïbes et en Amérique du Sud (Romero-Vivas et al., 2006 ; Quintero et al., 2014). Les larves d'Ae.aegypti sont également retrouvées dans des gîtes moins conventionnels comme les fosses septiques (Burke et al., 2010) et peuvent survivre dans des gîtes ayant des volumes d'eau très réduits (Luz et al., 2017). Ces caractéristiques témoignent de la grande adaptabilité du vecteur aux variations environnementales et favorise sa persistance pendant les saisons sèches (Kahamba et al., 2020). 
Les femelles gravides pondent souvent les œufs issus d'un même cycle gonotrophique dans plusieurs gîtes distincts (Reiter, 2007). Ce comportement de ponte dit «skip-oviposition » favorise la survie de la progéniture, la dispersion de l'espèce et par conséquent, le risque de propagation de la maladie (Reiter, 2007). Il est probable que cette stratégie permette d'éviter les risques de compétition intraspécifique et/ou de minimiser les risques de mortalité associés aux gîtes temporaires (Reiter, 2007).

Lors des stratégies de sélection des sites, les femelles en vol s'appuieraient également sur les composés organiques volatils (COVs) libérés par les micro-organismes présents dans l'eau (Figure 1). Ces derniers peuvent agir comme attractifs et/ou stimulants d'oviposition, ou à l'inverse constituer des répulsifs et/ ou inhibiteurs de ponte (Afify \& Galizia, 2015). Par exemple, des études expérimentales ont démontré que
18 genres bactériens dont Enterobacter, Pseudomonas, Bacillus, Klebsiella et Rhizobium sont impliqués dans cette attraction à la ponte (Ponnusammy et al., 2008).

En plus des métabolites microbiens, la femelle Ae. aegypti est influencée par des composés organiques émis par les larves conspécifiques. L'acide laurique et l'acide palmitoléique, retrouvés dans les œufs d'Ae.aegypti, et le n-hénéicosane d'origine larvaire, stimulent l'oviposition (Ganesan et al., 2006), tout comme les signaux indiquant une faible densité des larves dans l'eau (Wong et al., 2011). Cependant, ce pouvoir attractant diminue à mesure que la densité des larves augmente, possiblement pour éviter la compétition pour les ressources alimentaires (Day, 2016).

Enfin, la chimie de l'eau est également importante dans le choix du site de ponte. À la différence des facteurs biotiques, l'influence des propriétés abiotiques sur l'oviposition aurait surtout lieu lorsque les femelles

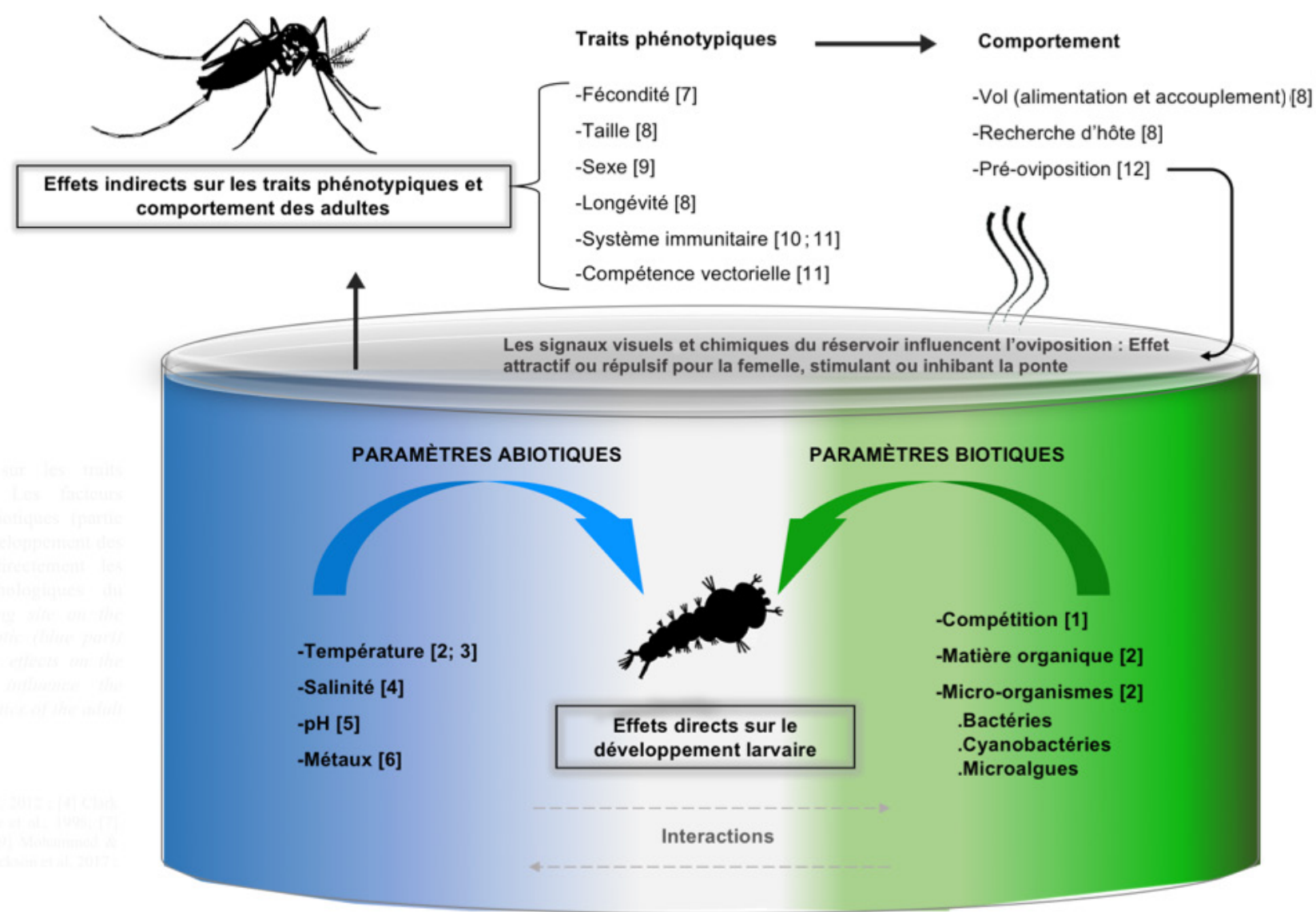

Figure 1. Influence du gîte larvaire sur les traits phénotypiques des moustiques adultes. Les facteurs abiotiques (partie bleue) et les facteurs biotiques (partie verte) du gîte ont des effets directs sur le développement des larves de moustiques et influencent indirectement les caractéristiques physiologiques et morphologiques du moustique adulte - Influence of the breeding site on the phenotypic traits of adult mosquitoes. Abiotic (blue part) and biotic (green part) factors have direct effects on the development of larvae and indirectly influence the physiological and morphological characteristics of the adult mosquito.

[1] Day, 2016 ; [2] Tun-Lin et al., 2000 ; [3] Farjana et al., 2012 ; [4] Clark et al., 2004 ; [5] Clark et al., 2007 ; [6] Rayms-Keller et al., 1998 ; [7] Scolari et al., 2019 ; [8] Reiskind \& Lounibos, 2009 ; [9] Mohammed \& Chadee, 2011 ; [10] Moreno-Garcia et al., 2015 ; [11] Dickson et al., 2017 ; [12] Ponnusammy et al., 2008. 
entrent en contact avec l'eau des récipients. En effet, il a été observé qu'Ae. aegypti «trempe » dans l'eau ses pattes et ses pièces buccales pourvues de chimiorécepteurs, lui permettant d'évaluer la qualité de l'eau (Matthews et al., 2019). Ainsi, une eau fortement concentrée en azote, phosphore et potassium (17 à $33 \mathrm{mg} \cdot \mathrm{l}^{-1}$ ) stimule la ponte (Darriet \& Corbel, 2008). Ces ions seraient alors des prédicteurs de la présence des larves d'Ae. aegypti dans les gîtes (Onchuru et al., 2016). À l'inverse, les femelles montrent une aversion pour les sites de ponte où l'eau de mer est présente (Matthews et al., 2019). Une corrélation négative est observée entre la salinité du gîte et le nombre moyen d'œufs, avec une absence totale de ponte lorsque la concentration de $\mathrm{NaCl}$ dans l'eau du gîte atteint $33 \mathrm{~g} \cdot \mathrm{l}^{-1}$ (Navarro et al., 2003). Malgré ces observations, les mécanismes physiologiques par lesquels un moustique évalue la composition de l'eau restent peu connus (Matthews et al., 2019).

\section{CARACTÉRISTIQUES PHYSICO- CHIMIQUES DE L'EAU DES GÎTES LARVAIRES D'AE. AEGYPTI}

En plus de leur effet sur le choix du site de ponte, les propriétés abiotiques des gîtes influencent grandement le développement des stades immatures d'Ae.aegypti. Il est actuellement admis qu'un gîte propice au développement des larves d'Ae. aegypti présente un $\mathrm{pH}$ proche de 7 , une température moyenne de $27^{\circ} \mathrm{C}$, une teneur en sel inférieure à $0,5 \mathrm{~g} \cdot \mathrm{l}^{-1}$, une conductivité moyenne comprise entre 100 et $700 \mu \mathrm{S} \cdot \mathrm{cm}^{-1}$, ainsi qu'une concentration en ions et métaux inférieure à $1 \mathrm{mg} \cdot \mathrm{l}^{-1}$ (Tableau 1). Cependant, sur le terrain, on observe une variabilité importante des profils physicochimiques des gîtes qui peuvent influencer le comportement de ponte, le développement larvaire ou encore la capacité vectorielle des adultes émergents (Tableau 1). La synthèse ci-dessous regroupe les données parcellaires existantes pour les paramètres abiotiques les plus étudiés chez les gîtes d'Ae. aegypti.

\subsection{Température}

La température est considérée comme l'un des paramètres abiotiques les plus importants dans le gîte larvaire et son effet sur le développement d'Ae. aegypti a été bien établi. Le moustique, étant ectotherme, dépend de la température de l'eau pour la régulation des activités enzymatiques nécessaires à la locomotion et à sa croissance (Abram et al., 2017). Les températures moyennes des différents récipients associés au développement du moustique Ae.aegypti sont très variables sur le terrain, avec des valeurs allant de $20{ }^{\circ} \mathrm{C}$ à $36{ }^{\circ} \mathrm{C}$ (Tableau 1). Ces variations seraient dues à la localisation géographique, la saisonnalité et la typologie du gîte (i.e. volume, matériel) (Barrera et al., 2006). Dans des conditions de laboratoire, des températures constantes comprises entre $24{ }^{\circ} \mathrm{C}$ et $30{ }^{\circ} \mathrm{C}$ favorisent l'éclosion et le développement des larves, alors que des températures hors de cette gamme entraînent une augmentation du temps de développement et du taux de mortalité (Tun-Lin et al., 2000 ; Mohammed \& Chadee, 2011 ; Farjana et al., 2012). Les températures constantes limites pour le développement d'Ae. aegypti sont de $15^{\circ} \mathrm{C}$ et $38^{\circ} \mathrm{C}$ (Tun-Lin et al., 2000 ; Carrington et al., 2013). Cela suggère qu'à la différence d'autres espèces telles qu'Ae.albopictus (Delatte et al., 2009), les populations d'Ae.aegypti ont une capacité plus limitée à supporter un stress thermique. Toutefois, dans l'environnement, les larves sont sujets aux fluctuations quotidiennes de la température de l'eau (Carrington et al., 2013). Ces variations peuvent modifier le temps de développement et la survie des larves, ainsi que certains traits d'histoire de vie des adultes (voir point 5) (Carrington et al., 2013). Ainsi, les études menées à température constante dans les laboratoires ne reflètent pas exactement les conditions du terrain. Malgré l'influence de la température sur le développement des larves, des températures similaires sont trouvées entre des containers positifs et des containers dépourvus de larves, soulignant que la température n'est pas indicatrice de la présence des stades immatures dans le gîte (Sultana et al., 2017).

\section{2. pH}

Les moustiques sont capables de réguler le $\mathrm{pH}$ de leur hémolymphe notamment grâce à des processus d'osmorégulation qui sont rapidement ajustés via des échanges osmotiques et ioniques (i.e. $\mathrm{H}^{+}, \mathrm{NH}_{4}^{+}$, $\mathrm{HCO}_{3}$ ) au niveau des papilles anales (Clark et al., 2007). Dans les gîtes larvaires, un $\mathrm{pH}$ proche de 7 s'avère optimal pour l'éclosion des œufs et le développement des larves (Clark et al., 2004). Cette valeur concorde avec celles enregistrées dans l'eau des gîtes d'Ae.aegypti de différentes régions, comprises entre 6 et 8 (Tableau 1). Cependant, quelques études rapportent la présence d'Ae.aegypti dans des eaux acides et alcalines avec des $\mathrm{pH}$ allant de 5 à 11 au Brésil et en Australie (Tun-Lin et al., 1995 ; Brito-Arduino et al., 2010). Cela a été confirmé en conditions de laboratoire, où les larves tolèrent des valeurs de $\mathrm{pH}$ variant de 4 à 11 (Clark et al., 2004), mais ces valeurs extrêmes impactent leur temps de développement. Malgré ces observations, le pH, peu variable sur le terrain, ne serait pas un indicateur de la présence des larves d'Ae. aegypti dans un récipient (Garcia-Sánchez et al., 2017 ; Saleh et al., 2018). 


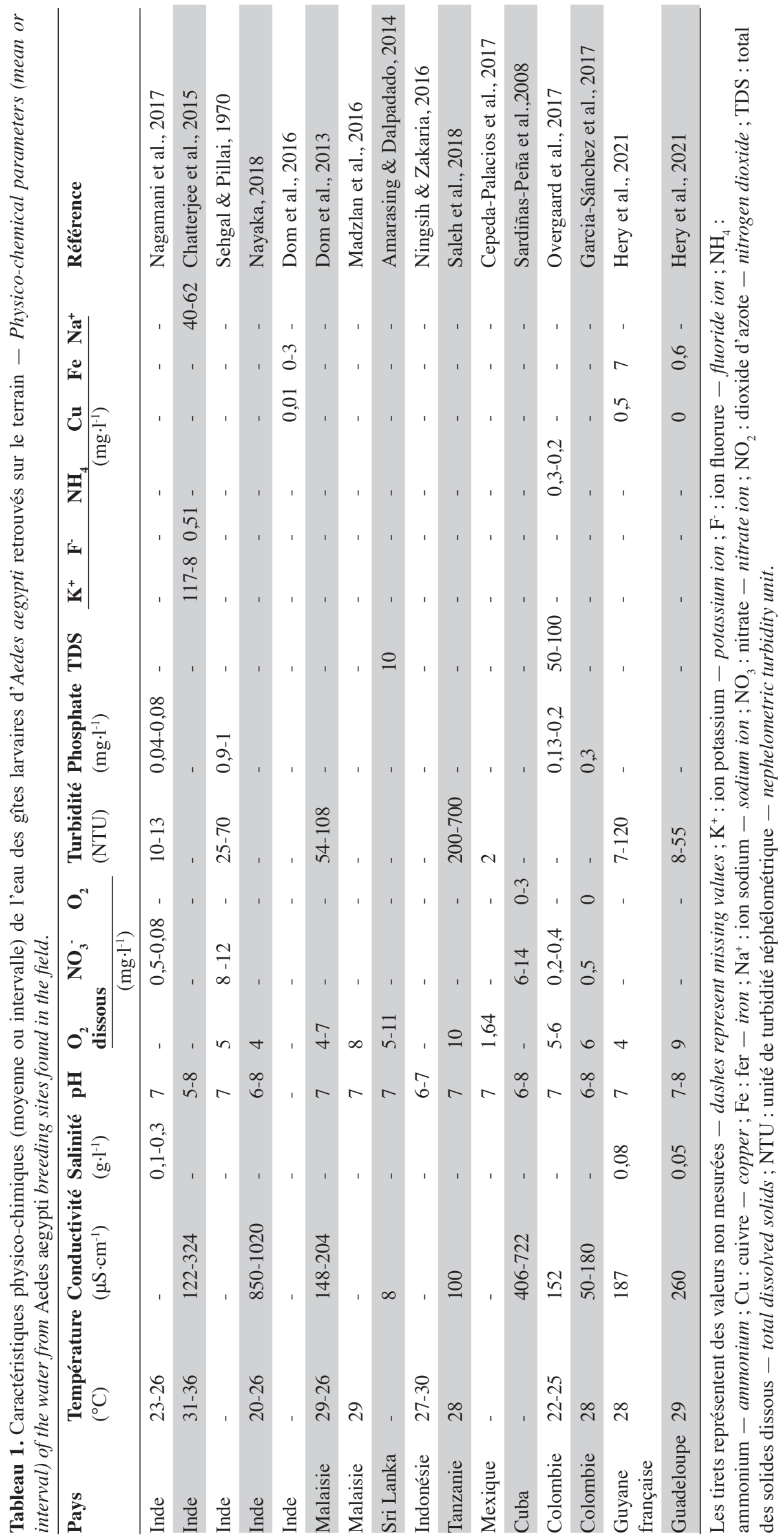

\subsection{Salinité}

Comme énoncé plus haut, la salinité peut influencer la sélection du gîte larvaire et l'oviposition chez Ae.aegypti (Matthews et al., 2019). Les données de terrain disponibles révèlent qu'Ae.aegypti se développe généralement dans des eaux douces, ayant une teneur en sel inférieure à $\quad 0,5 \mathrm{~g} \cdot \mathrm{l}^{-1} \quad$ (Tableau $\left.\mathbf{1}\right)$. Cependant, dans certaines localités côtières du Brésil et d'Asie, Ae.aegypti a été retrouvé dans des eaux saumâtres ayant une salinité pouvant atteindre $18 \mathrm{~g} \cdot \mathrm{l}^{-1}$ (Brito-Arduino et al., 2010 ; Surendran et al., 2012). Cette observation a été confortée par des données expérimentales qui montrent que les larves d'Ae.aegypti peuvent se développer dans l'eau ayant un niveau de salinité de $10 \mathrm{~g} \cdot \mathrm{l}^{-1}$ sans que le taux de survie ne soit significativement affecté par rapport aux larves élevées en eau douce (Navarro et al., 2003; Clark et al., 2004). Ces recherches suggèrent qu'Ae.aegypti est une espèce osmoconformiste pouvant entrer dans un état d'acclimatation en cas d'exposition à des salinités élevées. L'osmoconformisme d'Ae.aegypti peut lui permettre d'élargir sa niche écologique et de se développer davantage dans les eaux saumâtres en cas d'élévation du niveau de la mer, ce qui entrainerait un risque accru de transmission des arboviroses dans les zones côtières (Ramasamy \& Surendran, 2012).

\subsection{Turbidité et matière organique}

Le moustique Ae.aegypti est réputé pour se développer 
dans des «eaux claires » (moins de cinq unités de turbidité néphélométrique [NTU]). Cependant, des larves peuvent être retrouvées dans des gîtes qui ont une turbidité variant entre 20 et 100 NTU, soulignant qu'Ae. aegypti se développe aussi bien dans des habitats «d'eau claire» que «d'eau trouble» (Tableau 1). Leur développement en eau trouble semble possible grâce à la présence des bactéries et matières organiques qui peuvent servir de ressource alimentaire (Tun-Lin et al., 2000 ; Ponnusamy et al., 2008). Toutefois, la composition en matière organique dans l'eau peut impacter la densité des larves. En effet, l'abondance des larves est de manière générale positivement corrélée à la quantité de matière organique dans l'eau (Barrera et al., 2006 ; Overgaard et al., 2017). En revanche, la présence de certains végétaux dans le gîte (i.e. feuilles de manguier), de par leur propriétés antibactériennes et antifongiques, pourrait diminuer la densité des stades immatures d'Ae. aegypti (Tun-Lin et al., 2000 ; Aqil \& Ahmad, 2003).

\subsection{Teneur en oxygène dissous}

La larve d'Ae. aegypti respire l'oxygène atmosphérique par un siphon. Par conséquent, l'oxygène dissous dans l'eau ne constitue pas, en théorie, un obstacle direct à son développement (Clements, 2000). Les valeurs d'oxygène dissous recensées chez les gîtes d'Ae. aegypti à travers le monde varient de 4 à $10 \mathrm{mg} \cdot \mathrm{l}^{-}$ ${ }^{1}$ selon les récipients et les régions (Tableau 1). De manière générale, ces concentrations sont similaires à d'autres «gîtes potentiels » dépourvus de larves (Onchuru et al., 2016 ; Garcia-Sánchez et al., 2017). Des données expérimentales montrent qu'une faible quantité d'oxygène dissous dans le gîte (entre 0,5-2 $\left.\mathrm{mg} \cdot \mathrm{l}^{-1}\right)$ constituerait un important stimulus d'éclosion (Judson \& Gojrati, 1967). Bien qu'il ne soit pas encore établi si l' $\mathrm{O}_{2}$ dissous a une influence dans le comportement de ponte des femelles Ae.aegypti, des concentrations élevées d' $\mathrm{O}_{2}$ dissous (plus de $5 \mathrm{mg} \cdot \mathrm{l}^{-1}$ ) ont été positivement corrélées avec la présence de larves d'Ae. aegypti sur le terrain (Sultana et al., 2017).

\subsection{Conductivité et teneur en ions}

La conductivité associée aux gîtes larvaires d'Ae.aegypti est très variable sur le terrain, avec des valeurs comprises entre 50 et $1000 \mu \mathrm{S} \cdot \mathrm{cm}^{-1}$ (Tableau 1) et serait négativement corrélée avec l'abondance d'Ae.aegypti dans le gîte larvaire (Nagamani et al., 2017). Une forte conductivité est associée à une eau polluée en matière organique et minérale, riche en azote, phosphate et ammoniac (Assaad, 2014). Curieusement, il a été observé que des eaux ayant une forte densité de larves d'Ae.aegypti présentent une teneur plus élevée en azote ammoniacal $\left(\mathrm{NH}_{4}^{+}\right)$, en azote nitreux
$\left(\mathrm{NO}_{2}^{-}\right)$et en azote nitrique $\left(\mathrm{NO}_{3}^{-}\right)$par rapport aux eaux dépourvues de larves (Darriet \& Corbel, 2008). Ainsi, l'utilisation de la conductivité comme indicateur de la prolifération des moustiques devrait être étudiée davantage.

\subsection{Concentration en métaux}

Les concentrations en métaux lourds tels que le fer $(\mathrm{Fe})$, le zinc $(\mathrm{Zn})$ et le cuivre $(\mathrm{Cu})$ n'excèdent généralement pas $1 \mathrm{mg} \cdot \mathrm{l}^{-1}$ dans l'eau des gîtes d'Ae. aegypti, mais peuvent varier selon le type de conteneur (Tableau 1) (Dom et al., 2016). La pollution métallique peut contraindre l'éclosion des œufs et compromettre l'intégrité de la matrice péritrophique chez les larves d'Ae.aegypti (Rayms-Keller et al., 1998). Malgré cet impact non négligeable sur le développement de l'espèce, l'association des métaux avec la présence et l'abondance des larves d'Ae. aegypti reste peu étudiée.

\subsection{Le type de gîte}

La relation entre le type de gîte, le développement et l'abondance des larves d'Ae.aegypti est toujours mal comprise et d'une grande complexité. La diversité des types de gîtes en termes de dimensions, couleurs, textures et matériaux est à l'origine d'une grande variabilité des profils physicochimiques, ce qui peut influencer le développement des moustiques. En effet, une étude effectuée sur 161 gîtes larvaires en Guadeloupe et en Guyane a révélé que les fûts dans ces localités ont des profils physicochimiques caractéristiques avec des valeurs plus faibles de conductivité, turbidité et de minéraux (i.e. $\mathrm{Ca}, \mathrm{Mg}$ ) par rapport à d'autres types de gîtes comme les pneus (Hery et al., 2021). En outre, la couleur du gîte peut influencer la sélection du site de ponte par Ae. aegypti (Marin et al., 2020).

\section{COMPOSITION MICROBIENNE DE L'EAU DES GÎTES D'AE. AEGYPTI}

En plus de la variabilité des paramètres physicochimiques et leur influence sur le développement larvaire, un intérêt croissant est porté sur la diversité et composition du microbiote de l'eau des différents gîtes et leur interaction avec Ae.aegypti. Quelle que soit la région géographique, le phylum majoritairement présent dans l'eau des gîtes larvaires chez Ae. aegypti est Proteobacteria (>50\%), suivi des Firmicutes $(\simeq 15 \%)$, Bacteroidetes et Actinobacteria $(\simeq 10 \%)$ (Tableau 2). Au moins 16 familles bactériennes ont été détectées dans l'eau des gîtes, dont les plus courantes et dominantes sont Flavobacteriaceae, Comamonadaceae, Pseudomonadaceae, Bacillaceae, Microbacteraceae, 
Propriétés des gîtes d'Ae. aegypti et influence sur les moustiques adultes

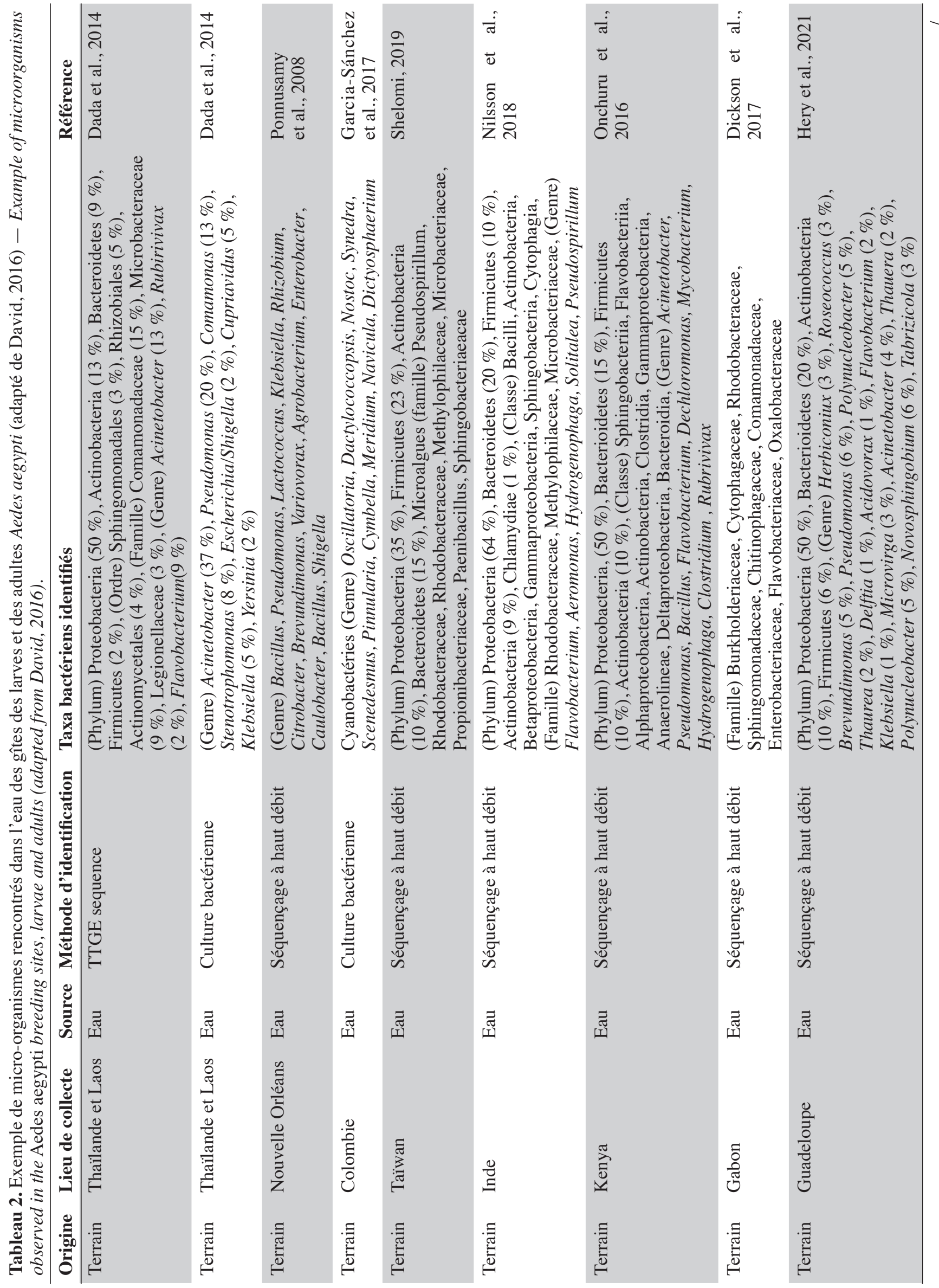




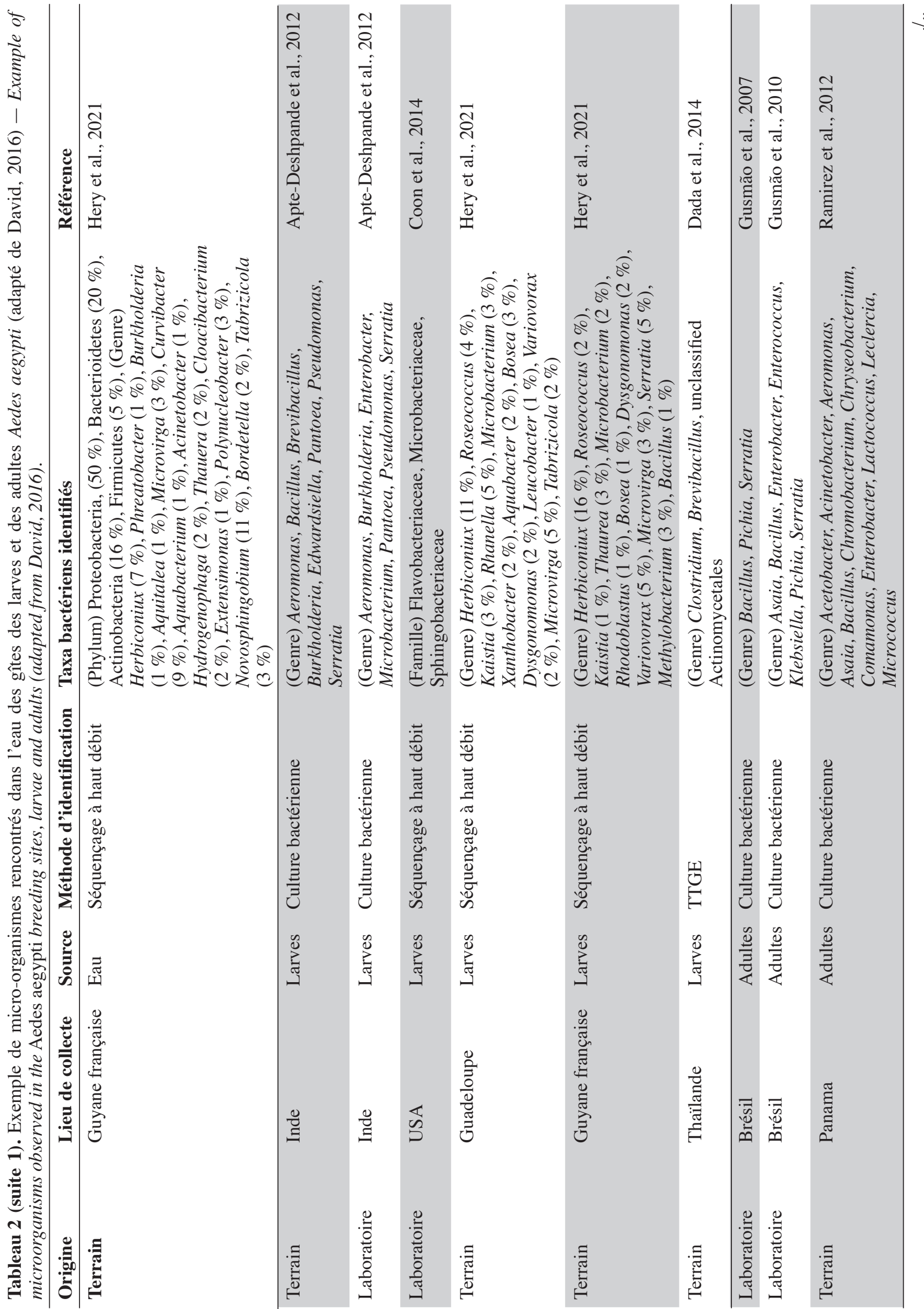


Propriétés des gîtes d'Ae.aegypti et influence sur les moustiques adultes

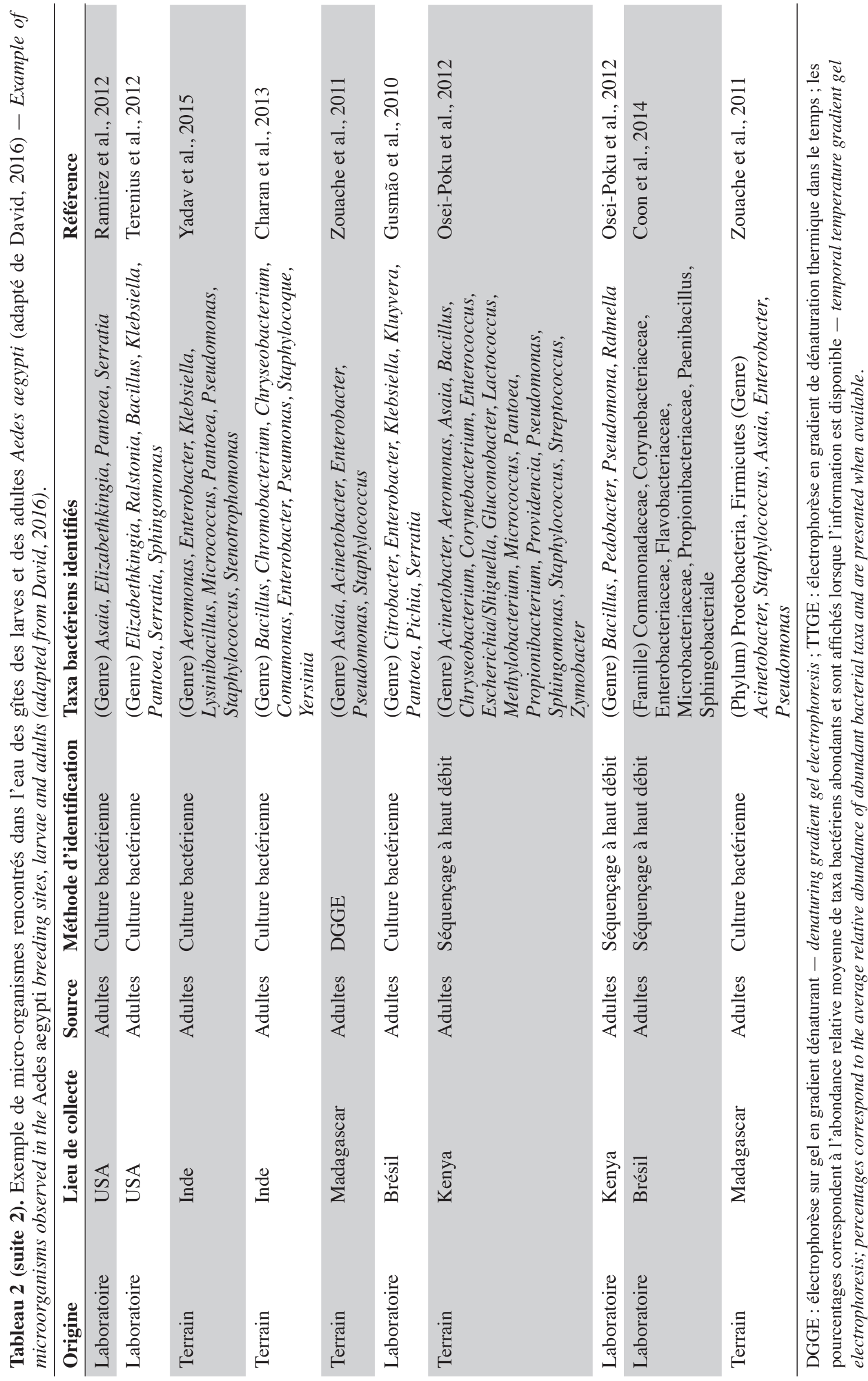


Rhodobacteraceae et Burkholderiaceae (Tableau 2). La majorité des gîtes comprennent des bactéries environnementales opportunistes appartenant aux genres Acinetobacter, Bacillus, Hydrogenophaga, Brevundimonas, Sphingomonas, Comamonas et Pseudomonas que l'on trouve dans diverses sources telles que l'eau, le sol ou les plantes (Coon et al., 2016). Cette fraction du microbiote qui est commune à tous les gîtes d'Ae. aegypti pourrait être indicatrice de la qualité de l'habitat pour ce vecteur (Duguma et al., 2013). En revanche, plus de la moitié des familles et genres retrouvés dans les gîtes d'Ae.aegypti (i.e. Hymenobacter, Methylocella, Chromobacterium, Burkholderia, Spirosoma, Rhodoccocus, Rubrobacteria, Thermoleophilia) sont minoritaires avec des abondances relatives inférieures à $1 \%$ et leur composition est variable d'un gîte à l'autre (Onchuru et al., 2016 ; Shelomi, 2019 ; Hery et al., 2021). Cette hétérogénéité du microbiote se reflète également par des variations de la richesse globale des bactéries observées dans les habitats d'Ae. aegypti (entre 200 et 5000 OTU par gîte) en fonction du type de récipient, la région géographique et/ou la saison (Coon et al., 2016 ; Dickson et al., 2017 ; Hery et al., 2021). Curieusement, la présence/absence de larves d'Ae a a gypti ne semble pas associée à une composition bactérienne particulière dans les eaux des lieux de reproduction existants ou potentiels (Dada et al., 2014 ; Shelomi, 2019). En effet, seul le groupe marin CL50029 appartenant à la famille des Acidimicrobiaceae a été identifié comme marqueur de l'absence de larves d'Ae.aegypti à ce jour (Nilsson et al., 2018). Ainsi, la structure spécifique des communautés bactériennes dans les gîtes domestiques n'est pas un facteur déterminant la présence de l'espèce, possiblement dû au grand nombre de redondances fonctionnelles retrouvées au sein de ces communautés. En plus des bactéries, un grand nombre de microalgues et des cyanobactéries ont été également retrouvés dans les gîtes larvaires d'Ae.aegypti (Garcia-Sánchez et al., 2017 ; Shelomi, 2019). Les familles de microalgues Bacillariophyceae, Chlorophyceae et le genre de cyanobactérie Oscillatoria font partie des taxa les plus communs et abondants retrouvés dans ces habitats aquatiques (Garcia-Sánchez et al., 2017 ; Shelomi, 2019). La présence des cyanobactéries dans les gîtes semble favoriser leur productivité et le développement larvaire puisque leur présence est positivement corrélée avec l'abondance des larves d'Ae.aegypti (Garcia-Sánchez et al., 2017).

La majorité des bactéries présentes dans l'eau des gîtes sont également retrouvées dans l'intestin des larves d'Ae.aegypti, dont environ la moitié (i.e. Acinetobacter, Pseudomonas et Bacillus) passe des premiers stades larvaires jusqu'aux adultes (Coon et al., 2016). Par conséquent, les modifications du microbiote des gîtes causées soit par des facteurs biotiques ou abiotiques, peuvent impacter le microbiote des moustiques adultes. Par exemple, les moustiques transmettent des bactéries aux gîtes pendant la ponte, ce qui affecte la communauté microbienne à laquelle les larves sont exposées (Coon et al., 2014 ; Nilsson et al., 2018). Cela favorise un certain niveau de transmission verticale et impacte la transmission du microbiote des larves aux adultes (Coon et al., 2016). Les facteurs environnementaux (i.e. la température, le $\mathrm{pH}$ et la teneur en oxygène) peuvent également influencer la croissance microbienne aquatique dans les gîtes et être à l'origine des variations du microbiote de l'intestin des moustiques adultes. En effet, l'augmentation de la température de l'eau peut favoriser la croissance des bêta-protéobactéries et la compétitivité des larves d'Anopheles spp. par rapport à celles du genre Aedes dans le gîte (Hortnagl et al., 2010 ; Onchuru et al., 2016). De plus, les antibiotiques résiduels dans l'eau réduisent ou éliminent certains taxa bactériens, impactant ainsi le microbiote des moustiques adultes (Scolari et al., 2019). Malgré l'importance de ces interactions de type dynamique hôte-symbionte, les connaissances disponibles sur le sujet sont toujours parcellaires. De plus, aucune étude ne s'est encore intéressée à l'influence de paramètres abiotiques de l'eau tels que l'oxygène dissous, la turbidité et les concentrations en métaux sur le microbiote de l'eau des gîtes et des moustiques adultes correspondants.

\section{EFFETS DES FACTEURS BIOTIQUES ET ABIOTIQUES DES GÎTES SUR LES TRAITS DE VIE DES ADULTES}

La variation naturelle des paramètres biotiques et abiotiques des gîtes d'Ae.aegypti peut impacter la biologie des moustiques adultes, notamment la taille du corps, sa longévité, sa fécondité ou encore leurs interactions avec certains arbovirus (Figure 1). Ici, nous rapportons les interactions entre les facteurs biotiques, abiotiques des gîtes larvaires et la biologie des adultes qui méritent une attention particulière au vu de leur utilité potentielle pour le contrôle des vecteurs.

\subsection{Influence sur la capacité reproductive et la longévité}

La température de l'eau est un facteur abiotique particulièrement important pour le développement des moustiques. En effet, il a été observé que les gîtes larvaires ayant une température élevée $\left(35^{\circ} \mathrm{C}\right)$ dans l'eau produisent des adultes Ae.aegypti de plus petite taille avec un temps de développement plus court (6-7 jours), contrairement à ceux se développant à des basses températures $\left(15^{\circ} \mathrm{C}\right)$ dont leur taille et temps de 
développement (40 jours) seront plus importants (TunLin et al., 2000). De plus, des températures élevées dans l'eau des gîtes peuvent modifier significativement le ratio mâles/femelles au profit des femelles, ce qui impacte la capacité vectorielle via une densité plus importante de vecteurs potentiels (Tun-Lin et al., 2000 ; Mohammed \& Chadee, 2011).

Les facteurs biotiques des gîtes larvaires influencent également les traits d'histoire de vie du moustique adulte. Par exemple, une quantité de matière organique insuffisante dans les gîtes lors du développement des larves peut également être associée à une réduction de la taille des ailes des moustiques adultes, à une longévité et une performance de vol plus courtes, ce qui impacte les capacités vectorielles et reproductives de l'espèce (Reiskind \& Lounibos, 2009). La qualité de la nourriture dans le gîte est également importante : les régimes bactériens (i.e. Serratia marcescens et Staphylococcus aureus) et à base de microalgues (i.e. Chlorella sp.) entraînent de faibles taux de survie des adultes par rapport aux larves nourries avec de la levure (Saccharomyces cerevisiae) (Souza et al., 2019). La qualité du gîte larvaire a donc un impact sur l'accumulation de réserves nutritives, facteur essentiel pour la production d'œufs chez Ae.aegypti ou pour le vol (Telang et al., 2006). En outre, les genres bactériens communément présents dans les habitats aquatiques d'Ae.aegypti comme Bacillus, Enterobacter et Serratia forment une partie du microbiote de l'intestin des moustiques adultes. Ces bactéries participent à la digestion sanguine grâce à leurs propriétés hémolytiques et sont également impliquées dans la productivité en œufs (Scolari et al., 2019). In fine, les propriétés abiotiques et biotiques des habitats aquatiques d'Ae. aegypti peuvent impacter la capacité vectorielle de l'espèce via des modifications de sa compétitivité, capacité reproductive (i.e. vol, fécondité, densité) et longévité.

\subsection{Influence sur la transmission des pathogènes}

En plus de son effet sur la taille et le vol, une nutrition insuffisante au stade larvaire peut être également associée à une plus grande sensibilité aux infections par arbovirus chez le moustique Ae.aegypti (Muturi et al., 2011). Des études expérimentales ont révélé que lorsque des larves sont exposées à une nutrition insuffisante, la sensibilité des adultes émergents à l'infection par le virus Sindbis ainsi que la capacité du virus à coloniser l'hémolymphe (dissémination) sont significativement plus importantes (Muturi et al., 2011). Ces différences de susceptibilité seraient liées à l'impact du stress nutritionnel sur les voies humorales (voies TOLL et Imd) et cellulaires (barrière intestinale ou hémocytes) du système immunitaire (Telang et al., 2012).
Les propriétés abiotiques des gîtes peuvent également influencer la compétence vectorielle d'Ae.aegypti (capacité du moustique à s'infecter, assurer le développement du pathogène et sa transmission). Les femelles Ae.aegypti exposées au stade larvaire à un choc thermique extrême $\left(45,5^{\circ} \mathrm{C}\right.$ pendant $10 \mathrm{~min}$ ) sont plus sensibles à l'infection par le VDEN (Yadav et al., 2005). Dans une étude similaire, une corrélation positive a été trouvée entre des intervalles croissants de stress thermique larvaire et une dissémination du VCHIK chez les femelles Ae.aegypti (Mourya et al., 2004). Les mécanismes par lesquels les facteurs de stress (i.e. malnutrition, compétition, température élevée) agissent pour augmenter la compétence vectorielle sont mal compris. Ils peuvent soit façonner la transmission directement par des effets sur la biologie des agents pathogènes, soit indirectement par des effets sur l'immunité et la physiologie des moustiques (Adelman et al., 2013). De manière intéressante, l'exposition à des températures élevées pendant le développement larvaire entraîne également chez ces moustiques une augmentation de l'expression de peptides antimicrobiens (PAM) (défensine et cécropine). Ces modifications altèrent le microbiote des moustiques adultes et les rendent plus vulnérables aux infections. En effet, le microbiote des adultes peut indirectement moduler leur système immunitaire inné et affecter la production de facteurs à activité antiparasitaire et antivirale (Scolari et al., 2019). C'est pourquoi il est probable que l'acquisition de certaines bactéries de l'eau des gîtes par les larves puisse influencer la compétence vectorielle des moustiques adultes via leur réponse immunitaire innée. Il a été démontré que l'exposition de larves axéniques d'Ae.aegypti à Escherichia coli stimule la production de PAM chez les femelles (Moreno-Garcia et al., 2015), ce qui pourrait limiter la propagation d'autres micro-organismes, comme les arbovirus. Une autre étude montre que des femelles Ae.aegypti qui ont subi différents traitements gnotobiotiques en tant que larves ont une réponse immunitaire innée différente, qui se traduit par une différence de dissémination du DENV (Dickson et al., 2017). Par ailleurs, l'exposition des larves à la bactérie Bacillus thuringiensis var israelensis (Bti) lors de leur développement a augmenté considérablement leur susceptibilité au DENV (Moltini-Conclois et al., 2018). Cela suggère que l'efficacité sous-optimale du Bti, connu comme larvicide, peut avoir des effets contre-productifs via l'augmentation de la compétence du vecteur vis-à-vis de cet arbovirus (Moltini-Conclois et al., 2018). Outre ces effets indirects des facteurs biotiques et abiotiques des gîtes larvaires, la possibilité d'une acquisition directe du virus Zika (ZIKV) par les larves et les pupes d'Ae.aegypti exposées à des faibles doses de ce virus dans des eaux d'égout a été 
récemment évoquée (Du et al., 2019). Curieusement, les adultes émergeant de ces gîtes avaient déjà la capacité à transmettre le ZIKV avec des particules virales infectieuses retrouvées dans leur salive (Du et al., 2019). Il est important de noter que l'influence du microbiote des moustiques adultes sur la transmission de pathogènes a été démontrée dans ces études via des approches expérimentales. Cependant, les conditions employées diffèrent sensiblement des conditions de terrain, caractérisées par une plus haute complexité d'interactions entre communautés microbiennes et facteurs environnementaux.

\section{CONCLUSIONS}

Étant donné qu'Ae. aegypti continue d'élargir son aire de distribution dans un contexte de réchauffement climatique et d'échanges commerciaux transnationaux, une bonne compréhension de sa biologie et écologie est indispensable. Bien que l'invasion du vecteur soit multifactorielle, elle repose initialement sur la plasticité écologique d'Ae.aegypti (i.e. capacité à coloniser différents environnements, types de gîtes) et sur la réceptivité de son milieu de développement.

Le développement de larves d'Ae.aegypti a lieu aujourd'hui dans des gîtes larvaires très diversifies ; l'espèce n'étant plus restreinte qu'aux « réservoirs d'eau propre ». L'état de l'art des connaissances autour des gîtes d'Ae.aegypti présenté dans cette synthèse suggère que les facteurs biotiques (microorganismes, matière organique, larves congénères) et abiotiques (salinité, température et conductivité) jouent un rôle important dans les processus de sélection des gîtes, le développement des stades immatures et la constitution des microbiomes larvaire et adulte (Figure 1). Cependant, peu d'études ont examiné cette influence sur le développement larvaire d'Ae.aegypti à travers des gradients de multiples conditions environnementales. De telles expériences sont nécessaires afin d'établir l'importance relative des facteurs environnementaux dans le choix des gîtes et le succès de développement de l'espèce. En même temps, les paramètres dominants liés à la distribution spatiale d'Ae. aegypti doivent être établis pour améliorer la conception d'un programme de lutte intégrée ciblant les stades immatures du vecteur. Enfin, nous avons cité des travaux démontrant que l'influence des bactéries du gîte sur la composition du microbiote des larves et des imagos peut également impacter des traits phénotypiques adultes sousjacents à la capacité vectorielle comme la capacité reproductive, la longévité et la compétence vectorielle (Figure 1). Dans ce contexte, des recherches évaluant comment l'exposition des moustiques aux paramètres biotiques et abiotiques des gîtes retrouvés sur le terrain influence la variabilité naturelle du microbiote des moustiques adultes et potentiellement la transmission de pathogènes, sont alors impérativement requises.

\section{Bibliographie}

Abílio A.P. et al., 2018. Distribution and breeding sites of Aedes aegypti and Aedes albopictus in 32 urban/periurban districts of Mozambique: implication for assessing the risk of arbovirus outbreaks. PLoS Negl. Trop. Dis., 12(9), e0006692, doi.org/10.1371/journal.pntd.0006692

Abram P.K., Boivin G., Moiroux J. \& Brodeur J., 2017. Behavioural effects of temperature on ectothermic animals: unifying thermal physiology and behavioural plasticity. Biol. Rev., 92(4), 1859-1876, doi.org/10.1111/ brv.12312

Adelman Z.N et al., 2013. Cooler temperatures destabilize RNA interference and increase susceptibility of disease vector mosquitoes to viral infection. PLoS Negl. Trop. Dis., 7(5), 1-8, doi.org/10.1371/journal.pntd.0002239

Afify A. \& Galizia C.G., 2015. Chemosensory cues for mosquito oviposition site selection. J. Med. Entomol., 52(2), 120-130, doi.org/10.1093/jme/tju024

Amarasing L.D. \& Dalpadado D.R., 2014. Vector mosquito diversity and habitat variation in a semi urbanized area of Kelaniya in Sri Lanka. Int. J. Entomol.Res., 2(1), 1521.

Apte-Deshpande A., Paingankar M., Gokhale M.D. \& Deobagkar D.N., 2012. Serratia odorifera a midgut inhabitant of Aedes aegypti mosquito enhances its susceptibility to dengue-2 virus. PLoS ONE, 7(7), e40401, doi.org/10.1111/j.1365-2915.2010.00864.x

Aqil F. \& Ahmad I., 2003. Broad-spectrum antibacterial and antifungal properties of certain traditionally used Indian medicinal plants. World J. Microbiol. Biotechnol., 19, 653-657, doi.org/10.1023/A:1025128104056

Assaad A., 2014. Pollution anthropique de cours d'eau : caractérisation spatio-temporelle et estimation des flux. Thèse de doctorat : Université de Lorraine (France).

Barrera R., Amador M. \& Clark G.G., 2006. Ecological factors influencing Aedes aegypti (Diptera: Culicidae) productivity in artificial containers in Salinas, Puerto Rico.J.Med.Entomol., 43(3), 484-492, doi.org/10.1093/ jmedent $/ 43.3 .484$

Brito-Arduino M., Marques G. \& Serpa LLN., 2010. Registro de larvas e pupas de Aedes aegypti e Aedes albopictus em recipientes com água salina em condições naturais [Record of larvae and pupae of Aedes aegypti and Aedes albopictus in containers with saline water in natural conditions]. Bol. Epidemiol. Paulista (BEP A), 83(7), 228.

Burke R. et al., 2010. Septic tanks as larval habitats for the mosquitoes Aedes aegypti and Culex quinquefasciatus in Playa-Playita, Puerto Rico. Med. Vet. Entomol., 24(2), 117-123, doi.org/10.1111/j.1365-2915.2010.00864.x 
Carrington L.B. et al., 2013. Effects of fluctuating daily temperatures at critical thermal extremes on Aedes aegypti life-history traits. PLoS ONE, 8, e58824, doi. org/10.1371/journal.pone.0058824

Cepeda-Palacios R. et al., 2017. Environmental factors favoring the proliferation of Aedes aegypti (Linnaeus 1762) larvae in livestock water troughs at a suburban area of La Paz, Mexico. Southwest. Entomolog., 42(3), 795-803, doi.org/10.3958/059.042.0318

Charan S.S. et al., 2013. Comparative analysis of midgut bacterial communities of Aedes aegypti mosquito strains varying in vector competence to dengue virus. Parasitol. Res., 112(7), 2627-2637, doi.org/10.1007/ s00436-013-3428-x

Chatterjee S., Chakraborty A. \& Sinha S.K., 2015. Spatial distribution \& physicochemical characterization of the breeding habitats of Aedes aegypti in \& around Kolkata, West Bengal, India. Indian J. Med. Res., 142(Suppl 1), S79, doi.org/10.4103/0971-5916.176631

Clark T.M., Flis B.J. \& Renold S.K., 2004. pH tolerances and regularity abilities of fresh water and euryhaline Aedes mosquito larvae (Insecta: Diptera, Culicidae). J. Exp. Biol., 207, 2297-2304, doi.org/10.1242/ jeb. 01021

Clark T.M. et al., 2007. Strategies for regulation of hemolymph $\mathrm{pH}$ in acidic and alkaline water by the larval mosquito Aedes aegypti (L.) (Diptera; Culicidae). J. Exp. Biol., 210(24), 4359-4367, doi.org/10.1242/ jeb.010694

Clements A.N., 2000. The biology of mosquitoes. Vol.1: development, nutrition and reproduction. Wallingford, UK: CABI Publishing.

Coon K.L., Vogel K.J., Brown M.R. \& Strand M.R., 2014. Mosquitoes rely on their gut microbiota for development. Mol. Ecol., 23(11), 2727-2739, doi. org/10.1111/mec.12771

Coon K.L., Brown M.R. \& Strand M.R., 2016. Mosquitoes host communities of bacteria that are essential for development but vary greatly between local habitats. Mol. Ecol., 25(22), 5806-5826, doi.org/10.1111/ mec. 13877

Dada N. et al., 2014. Comparative assessment of the bacterial communities associated with Aedes aegypti larvae and water from domestic water storage containers. Parasites Vectors, 7(1), 391, doi.org/10.1186/17563305-7-391

Darriet F. \& Corbel V., 2008. Propriétés attractives et modifications physicochimiques des eaux de gîtes colonisées par des larves de Aedes aegypti (Diptera : Culicidae). C.R. Biol., 331(8), 617-622, doi. org/10.1016/j.crvi.2008.05.003.

David M.R, 2016. Avaliação de aspectos das interações envolvendo o vetor Aedes aegypti, a microbiota intestinal e arbovírus. Thèse de doctorat: Fundação Oswaldo Cruz, Instituto Oswaldo Cruz, Rio de Janeiro (Brasil).
Day J.F., 2016. Mosquito oviposition behavior and vector control. Insects, 7(4), 65, doi.org/10.3390/ insects 7040065

Delatte H., Gimonneau G., Triboire A. \& Fontenille D., 2009. Influence of temperature on immature development, survival, longevity, fecundity, and gonotrophic cycles of Aedes albopictus, vector of chikungunya and dengue in the Indian Ocean. J. Med. Entomol., 46(1), 33-41, doi. org/10.1603/033.046.0105

Dickson L.B. et al., 2017. Carryover effects of larval exposure to different environmental bacteria drive adult trait variation in a mosquito vector. $S c i$. $A d v$., 3(8), e1700585, doi.org/10.1126/sciadv.1700585

Dom N.C., Ahmad A.H. \& Ismail R., 2013. Habitat characterization of Aedes sp. breeding in urban hotspot area. Procedia-Social Behav. Sci., 85, 100-109, doi. org/10.1016/j.sbspro.2013.08.342

Dom N.C. et al., 2016. Water quality characteristics of dengue vectors breeding containers. Int. J. Mosq. Res., 3(1), 25-9.

Du S. et al., 2019. Aedes mosquitoes acquire and transmit Zika virus by breeding in contaminated aquatic environments. Nature Commun., 10(1), 1-11, doi. org/10.1038/s41467-019-09256-0

Duguma D. et al., 2013. Bacterial communities associated with Culex mosquito larvae and two emergent aquatic plants of bioremediation importance. PLoS One, 8(8), doi.org/10.1371/journal.pone.0072522

Farjana T., Tuno N. \& Higa Y., 2012. Effects of temperature and diet on development and interspecies competition in Aedes aegypti and Aedes albopictus. Med. Vet. Entomol., 26(2), 210-217, doi.org/10.1111/j.13652915.2011.00971.x

Ferdousi F. et al., 2015. Identification of essential containers for Aedes larval breeding to control dengue in Dhaka, Bangladesh. Trop. Med. Health, 43(4), 253-264, doi. org/10.2149/tmh.2015-16

Ganesan K. et al., 2006. Studies of Aedes aegypti (Diptera: Culicidae) ovipositional responses to newly identified semiochemicals from conspecific eggs. Austr. J. Entomol., 45(1), 75-80, doi.org/10.1111/j.14406055.2006.00513.x

Garcia-Sánchez D.C., Pinilla G.A. \& Quintero J., 2017. Ecological characterization of Aedes aegypti larval habitats (Diptera: Culicidae) in artificial water containers in Girardot, Colombia. J. Vector Ecol., 42(2), 289-297, doi.org/10.1111/jvec.12269

Gusmão D.S. et al., 2007. First isolation of microorganisms from the gut diverticulum of Aedes aegypti (Diptera: Culicidae): new perspectives for an insect-bacteria association. Memórias Inst. Oswaldo Cruz, 102(8), 919924, doi.org/10.1590/s0074-02762007000800005

Gusmão D.S. et al., 2010. Culture-dependent and cultureindependent characterization of microorganisms associated with Aedes aegypti (Diptera: Culicidae) (L.) and dynamics of bacterial colonization in the midgut. 
Acta Tropica, 115(3), 275-281, doi.org/10.1016/j. actatropica.2010.04.011

Hery L. et al., 2021. Natural variation in physicochemical profiles and bacterial communities associated with Aedes aegypti breeding sites and larvae on Guadeloupe and French Guiana. Microb. Ecol., 81(1), 93-109, doi. org/10.1007/s00248-020-01544-3

Hortnagl P.etal.,2010. The bacterial community composition of the surface microlayer in a high mountain lake. FEMS Microbiol. Ecol., 73, 458-467, doi.org/10.1111/j.15746941.2010.00904.x

Islam S., Haque C.E., Hossain S. \& Rochon K., 2019. Role of container type, behavioural, and ecological factors in Aedes pupal production in Dhaka, Bangladesh: an application of zero-inflated negative binomial model. Acta Tropica, 193, 50-59, doi.org/10.1016/j. actatropica.2019.02.019

Judson C.L. \& Gojrati H.A., 1967. The effects of various oxygen tensions on embryogeny and larval responses of Aedes aegypti. Entomol. Exp. Appl., 10(2), 181-188, doi. org/10.1111/j.1570-7458.1967.tb00057.x

Kahamba N.F. et al., 2020. Habitat characteristics and insecticide susceptibility of Aedes aegypti in the Ifakara area, south-eastern Tanzania. Parasites Vectors, 13(1), 53, doi.org/10.1186/s13071-020-3920-y

Luz C. et al., 2017. Survival and development of immature Aedes aegypti in artificial desiccating breeding sites under laboratory conditions. J. Appl. Entomol., 141, 315321, doi.org/10.1111/jen.12348

Madzlan F., Dom N.C., Tiong C.S. \& Zakaria N., 2016. Breeding characteristics of Aedes mosquitoes in dengue risk area. Procedia-Social Behav. Sci., 234, 164-172.

Marin G., Mahiba B., Arivoli S. \& Tennyson S., 2020. Does colour of ovitrap influence the ovipositional preference of Aedes aegypti Linnaeus 1762 (Diptera: Culicidae). Int. J. Mosq. Res., 7(2), 11-15.

Matthews B.J., Younger M.A. \& Vosshall L.B., 2019. The ion channel ppk301 controls freshwater egg-laying in the mosquito Aedes aegypti. Elife, 8, e43963, doi. org/10.7554/eLife.43963.001

Mohammed A. \& Chadee D.D., 2011. Effects of different temperature regimens on the development of Aedes aegypti (L.) (Diptera: Culicidae) mosquitoes. Acta Tropica, 119(1), 38-43, doi.org/10.1016/j. actatropica.2011.04.004

Moltini-Conclois I. et al., 2018. Larval exposure to the bacterial insecticide BTI enhances dengue virus susceptibility of adult Aedes aegypti mosquitoes. Insects, 9(4), 193, doi.org/10.3390/insects9040193

Moreno-García M. et al., 2015. Bacterial exposure at the larval stage induced sexual immune dimorphism and priming in adult Aedes aegypti mosquitoes. Plos ONE, 10(7), doi.org/10.1371/journal.pone.0133240

Mourya D.T., Yadav P. \& Mishra A.C., 2004. Effect of temperature stress on immature stages and susceptibility of Aedes aegypti mosquitoes Chikungunya virus. Am. J. Trop. Med. Hyg., 70, 346-350.

Muturi E.J. et al., 2011. Larval environmental stress alters Aedes aegypti competence for Sindbis virus. Trop. Med. Int. Health, 16(8), 955-964, doi.org/10.1111/j.13653156.2011.02796.x

Nagamani S. et al., 2017. Physicochemical characteristics and seasonal variations of the habitats in relation to the density of dengue vector Aedes aegypti in Kumbakonam, Tamil Nadu, India. IMPACT, 5(12), 21-26.

Navarro D. et al., 2003. The potential attractant or repellent effects of different water types on oviposition in Aedes aegypti L. (Dipt., Culicidae). J. Appl. Entomol., 127(1), 46-50, doi.org/10.1046/j.1439-0418.2003.00690.x

Nayaka B.S., 2018. Physico-chemical characteristics of larval habitat waters of mosquitoes in and around Bangalore, Karnataka, India. Int. J. Entomol. Res., 3(2), 177-179.

Nilsson L.K. et al., 2018. Presence of Aedes and Anopheles mosquito larvae is correlated to bacteria found in domestic water-storage containers. FEMS Microbiol. Ecol., 94(6), fiy058, doi.org/10.1093/femsec/fiy058

Ningsih F.\&Zakaria I.J.,2016. The microhabitat preferences of mosquito genus Aedes (Diptera: Culicidae) in Padang, West Sumatra, Indonesia. Int. J. Mosq. Res., 3, 36-40.

Onchuru T.O. et al., 2016. Chemical parameters and bacterial communities associated with larval habitats of Anopheles, Culex and Aedes mosquitoes (Diptera: Culicidae) in western Kenya. Int. J. Trop. Insect Sci., 36(3), 146-160, doi.org/10.1017/S1742758416000096

OMS (Organisation Mondiale de la Santé), 2009. Dengue-Guidelines for diagnosis, treatment, prevention and control, apps.who.int/iris/bitstream/ handle/ $10665 / 44188 / 9789241547871$ _eng . pdf?sequence=1\&isAllowed=y, (09/03/2021).

OMS (Organisation Mondiale de la Santé), 2011. Operational guide for assessing the productivity of Aedes aegypti breeding sites, www.who.int/tdr/publications/ documents/sop-pupal-surveys.pdf?ua=1, (09/03/2021).

Osei-Poku J., Mbogo C.M., Palmer W.J. \& Jiggins F.M., 2012. Deep sequencing reveals extensive variation in the gut microbiota of wild mosquitoes from Kenya. Mol. Ecol., 21(20), 5138-5150, doi.org/10.1111/j.1365294x.2012.05759.x

Overgaard H.J. et al., 2017. A cross-sectional survey of Aedes aegypti immature abundance in urban and rural household containers in central Colombia. Parasites Vectors, 10(1), 356, doi.org/10.1186/s13071-017-2295-1

Philbert A. \& Ijumba J.N., 2013. Preferred breeding habitats of Aedes aegypti (Diptera: Culicidae) mosquito and its public health implications in Dares Salaam, Tanzania. J. Environ. Manage., 4(10), 344-351.

Ponnusamy L. et al., 2008. Identification of bacteria and bacteria-associated chemical cues that mediate oviposition site preferences by Aedes aegypti. PNAS, 105(27), 9262-9267, doi.org/10.1073/pnas.0802505105 
Quintero J. et al., 2014. Ecological, biological and social dimensions of dengue vector breeding in five urban settings of Latin America: a multi-country study. BMC Infect. Dis., 14(1), 1-13, doi.org/10.1186/1471-2334-1438

Ramasamy R. \& Surendran S.N., 2012. Global climate change and its potential impact on disease transmission by salinity-tolerant mosquito vectors in coastal zones. Front. Physiol., 3, 198, doi.org/10.3389/ fphys.2012.00198

Ramirez J.L. et al., 2012. Reciprocal tripartite interactions between the Aedes aegypti midgut microbiota, innate immune system and dengue virus influences vector competence. PLoS Negl. Trop. Dis., 6, e1561, doi. org/10.1371/journal.pntd.0001561

Rayms-Keller A. et al., 1998. Effect of heavy metals on Aedes aegypti (Diptera: Culicidae) larvae. Ecotoxicol. Environ. Saf., 39(1), 41-7.

Reiskind M.H. \& Lounibos L.P., 2009. Effects of intraspecific larval competition on adult longevity in the mosquitoes Aedes aegypti and Aedes albopictus. Med. Vet. Entomol., 23(1), 62-68, doi.org/10.1111/j.13652915.2008.00782.x

Reiter P., 2007. Oviposition, dispersal, and survival in Aedes aegypti: implications for the efficacy of control strategies. Vector-Borne Zoonotic Dis., 7(2), 261-273, doi.org/10.1089/vbz.2006.0630

Romero-Vivas C.M.E., Arango-Padilla P. \& Falconar A.K.I., 2006. Pupal-productivity surveys to identify the key container habitats of Aedes aegypti (L.) in Barranquilla, the principal seaport of Colombia. Ann. Trop. Med. Parasitol., 100(sup1), 87-95, doi. org/10.1179/136485906X105543

Saleh F. et al., 2018. Habitat characteristics for immature stages of Aedes aegypti in Zanzibar city, Tanzania. J. Am. Mosq. Control Assoc., 34(3), 190-200, doi. org/10.2987/17-6709.1

Sardiñas-Peña O., García-Melían M., Castillo I. \& Fernández-Novo M., 2008. Evaluación físico-química del agua de depósitos positivos a focos de Aedes aegypti. Rev. Cubana Higiene Epidemiología, 46(2).

Scolari F., Casiraghi M. \& Bonizzoni M., 2019. Aedes spp. and their microbiota: a review. Front. Microbiol., 10, 2036, doi.org/10.3389/fmicb.2019.02036

Sehgal S.S. \& Pillai M.K., 1970. Preliminary studies on the chemical nature of mosquito-breeding waters in Delhi. Bull. World Health Organ., 42(4), 647-650.

Shelomi M., 2019. Bacterial and eukaryote microbiomes of mosquito habitats in dengue-endemic southern Taiwan. J. Asia-Pacific Entomol., 22(2), 471-480, doi. org/10.1016/j.aspen.2019.02.011

Silva J.V. et al., 2018. Current status, challenges and perspectives in the development of vaccines against yellow fever, dengue, Zika and chikungunya viruses. Acta Trop., 182, 257-263, doi.org/10.1016/j. actatropica.2018.03.009
Souza R.S et al., 2019. Microorganism-based larval diets affect mosquito development, size and nutritional reserves in the yellow fever mosquito Aedes aegypti (Diptera: Culicidae). Front. Physiol., 10, 152, doi. org/10.3389/fphys.2019.00152

Souza-Neto J.A., Powell J.R. \& \& Bonizzoni M., 2019. Aedes aegypti vector competence studies: a review. Infect. Genet. Evol., 67, 191-209, doi.org/10.1016/j. meegid.2018.11.009

Sultana A. et al., 2017. Larval breeding habitats and ecological factors influence the species composition of mosquito (Diptera: Culicidae) in the parks of Dhaka city, Bangladesh. Bangladesh J. Zool., 45(2), 111-122, doi. org/10.3329/bjz.v45i2.35706

Surendran S.N. et al., 2012. Pre-imaginal development of Aedes aegypti in brackish and fresh water urban domestic wells in Sri Lanka. J. Vector Ecol., 37(2), 471-473, doi. org/10.1111/j.1948-7134.2012.00254.x

Telang A., Li Y., Noriega F.G. \& Brown M.R., 2006. Effects of larval nutrition on the endocrinology of mosquito egg development. J. Exp. Biol., 209(4), 645-655, doi. org/10.1242/jeb.02026

Telang A. et al., 2012. Larval nutritional stress affects vector immune traits in adult yellow fever mosquito Aedes aegypti (Stegomyia aegypti). Med. Vet. Entomol., 26(3), 271-281, doi.org/10.1111/j.1365-2915.2011.00993.x

Terenius O. et al., 2012. Midgut bacterial dynamics in Aedes aegypti. FEMS Microbiol. Ecol., 80, 556-565, doi. org/10.1111/j.1574-6941.2012.01317.x

Tun-Lin W., Kay B.H. \& Barnes A., 1995. Understanding productivity, a key to Aedes aegypti surveillance. Am.J. Trop. Med. Hyg., 53(6), 595-601.

Tun-Lin W., Burkot T.R. \& Kay B.H., 2000. Effects of temperature and larval diet on development rates and survival of the dengue vector Aedes aegypti in north Queensland, Australia. Med.Vet.Entomol., 14(1), 31-37, doi.org/10.1046/j.1365-2915.2000.00207.x

Wong J. et al., 2011. Oviposition site selection by the dengue vector Aedes aegypti and its implications for dengue control. PLoS Negl. Trop. Dis., 5(4), doi.org/10.1371/ journal.pntd.0001015

Yadav K.K. et al., 2015. Molecular characterization of midgut microbiota of Aedes albopictus and Aedes aegypti from Arunachal Pradesh, India. Parasites Vectors, 8, 641, doi.org/10.1186/s13071-015-1252-0

Yadav P. et al., 2005. Effect of temperature and insecticide stresses on Aedes aegypti larvae and their influence on the susceptibility of mosquitoes to dengue-2 virus. Southeast Asian J. Trop. Med. Public Health, 36(5), 1139.

Zouache K. et al., 2011. Bacterial diversity of field-caught mosquitoes, Aedes albopictus and Aedes aegypti, from different geographic regions of Madagascar. FEMS Microbiol. Ecol., 75(3), 377-389, doi.org/10.1111/ j.1574-6941.2010.01012.x

(88 réf.) 